\title{
La imagen y la expectativa frente a la realidad de Villavicencio como destino turístico
}

\author{
Image and expectations regarding the reality of Villavicencio as a tourist \\ destination
}

\section{A imagem e a expectativa frente à realidade de Villavicencio como destino turístico}

\section{María C. Otero-Gómez ${ }^{1}$, Wilson Giraldo-Pérez ${ }^{2}$, Duván E. Ramírez - Ospina ${ }^{3}$}

Profesional en Comercio Internacional, MSc. Escuela de Administración y Negocios. Facultad de Ciencias Económicas Universidad de los Llanos.

Administrador de Empresas, MSc. Director Especialización en Desarrollo de Mercados. Facultad de Ciencias Económicas. Universidad de los Llanos.

Economista, MSc, Doctor en Administración, Decano Facultad de Ciencias Económicas, Administrativas y Contables. Universidad de Manizales

Email:motero@unillanos.edu.co

\section{Resumen}

El objetivo de la investigación fue analizar las dinámicas de consumo que presenta el turista en la ciudad de Villavicencio (Colombia). En esta ciudad la planeación turística se ha estructurado teniendo en cuenta elementos de la oferta, sin involucrar la demanda, representada en las expectativas y deseos de los consumidores turistas, lo que dificulta la generación de estrategias tendientes a su fidelización. Se utilizó la metodología cuantitativa. Se plantearon tres hipótesis, los datos recolectados de las 385 encuestas se procesaron en SPSS versión 18. Los resultados permiten observar que la expectativa de los turistas respecto al destino varía según las imágenes que se tienen de forma a priori y a posteriori, para ajustarse, finalmente, a las condiciones reales encontradas en Villavicencio.

Palabras clave: imaginario turístico, evaluación, producto turístico.

\section{Abstract}

The objective of the research was to analyze the dynamics of consumption of tourist in Villavicencio city (Colombia). In this place tourism planning has been structured taking into account elements of the offer, without involving the demand, displayed in the expectations and desires of consumers tourists, which hinders the generation of strategies to their loyalty. Quantitative methodology was used. Were three hypotheses raised, the data collected from 385 surveys were processed using SPSS version 18. The role of clusters in K-means, and correlations between Spearman and chi-square tests were used to perform descriptive and inferential 
analyzes. The results allow us to observe that the expectation of tourists about the place destiny changes according to the ideas they have a priori and a posteriori, and are finally adjusted to actual conditions founded in Villavicencio.

Key words: tourism image, evaluation, tourist product.

\section{Resumo}

O objetivo da pesquisa foi analisar a dinâmica do consumo que apresenta o turista na cidade de Villavicencio (Colômbia). Nesta cidade o planejamento turístico se há estruturado tendo em conta elementos a partir da oferta, sem involucrar a posição da demanda, representada nas expectativas e desejos dos consumidores turistas, o qual dificulta a geração de estratégias tendentes a sua fidelização. Foi utilizada a metodologia quantitativa. Foram formuladas três hipóteses, os dados recolhidos de 385 entrevistas, processadas em SPSS versão 18. Os resultados permitem observar que a expectativa dos turistas em relação ao destino varia de acordo com as imagens que temos de como a priori e a posteriori, para finalmente ajustado para as condições reais encontradas em Villavicencio como um destino turístico.

Palavras chave: imaginário turístico, evaluação, produto turístico.

\section{Introducción}

El turismo es considerado como una de las actividades sociales y económicas más importantes para cualquier país. El Ministerio de Comercio Industria y Turismo de Colombia, lo define como el fenómeno resultante de la coincidencia inmediata o mediata de diversos factores que se generan por el desplazamiento temporal de personas, que teniendo entre otros motivos, la recreación y el descanso, visitan lugares diferentes al de su domicilio habitual e intercambian por dinero, bienes y servicios para la realización de actos particulares de consumo (Mincomercio, 2013). Con esta visión, el turismo destaca dos elementos fundamentales. El primero está asociado con el aporte a la economía en la región específica donde se desarrolla dicha actividad, si se tiene en cuenta la generación de empleos, el mejoramiento de la infraestructura vial, hotelera y de servicios conexos al turismo. El segundo se refiere al consumo de los bienes y servicios derivados de la actividad turística, donde intervienen elementos sociales y culturales.
Adicionalmente, es necesario estudiar los factores que generan el desplazamiento temporal de personas, los cuales en la mayoría de casos se basan en las expectativas que tienen sobre un destino. El término expectativa de los turistas debe ser entendido como el fenómeno de anticipación de un resultado futuro, respecto a los hallazgos que ofrece el destino turístico. Son una red de creencias desarrolladas a partir de las experiencias de aprendizaje, éstas pueden ser positivas o negativas y son consideradas como una variable predictiva del consumo (Sheeran y Abraham, 1996).

Las expectativas positivas hacen referencia a los elementos favorables que le gustaría encontrar al turista en Villavicencio y que pueden incidir en la fidelización del cliente y que el destino pueda ser competitivo frente a otros.

La construcción de la imagen turística cobra importancia debido a que forma parte de los elementos motivacionales que influyen en la selección del destino y, una vez establecida las categorías de consumidores turísticos que

La imagen y la expectativa frente a la realidad de Villavicencio como destino turístico 
se ajustaron a Villavicencio, se procedió a analizar la evaluación que el turista hizo del destino.

Un destino turístico puede contar con atributos que atraen la atención del consumidor, pero es fundamental conocer plenamente lo que éste desearía encontrar con el fin de entender sus hábitos de compra, diseñar y posicionar servicios turísticos que satisfagan las expectativas de los turistas. En palabras de Páramo (2004), aunque las oportunidades están presentes, es necesario aceptar que para el marketing son más importantes los hábitos de consumo que los de compra, en la medida en que es el consumo el que le imprime un especial impulso a toda la actividad económica.

El objetivo de la investigación consistió en analizar las dinámicas de consumo que presenta el turista en la ciudad de Villavicencio y la evaluación de satisfacción que hace de esta ciudad.

\section{Materiales y metodos}

\section{- Diseño}

El trabajo de campo tuvo una duración de diez meses entre 2011 y 2012. La fuente primaria fueron los turistas de diversas edades a quienes se les aplicaron instrumentos in situ en los eventos específicos: Feria Agroindustrial, equina, bovina, turística y cultural del Meta que se realiza en el mes de enero; el Torneo Internacional del Joropo desarrollado en el mes de Junio y en el Encuentro Mundial de Coleo que se celebra en Octubre. Los instrumentos implementados fueron formato de encuesta estructurada.

La investigación adoptó la clasificación de sustantiva propuesta por Selltiz et al., (1974), con niveles descriptivo y correlacional. Se implementó un diseño bibliográfico y de campo, basado en análisis de datos primarios con un corte transversal para determinar según la fidelidad, los segmentos de turistas que arribaron a Villavicencio y, datos secundarios para comprender los cambios en las tipologías del turista en el periodo 2004-2010.

Durante el desarrollo de la investigación se tuvieron en cuenta tres hipótesis. La primera consistió en proponer que cuanto más favorable sea la imagen que se tenga a priori de Villavicencio como destino turístico, mayores serán las expectativas del individuo sobre su futura experiencia turística. La segunda se refirió a que cuanto mayor sea la expectativa de los consumidores turísticos acerca de la ciudad de Villavicencio, menor será su nivel de satisfacción del destino y por tanto la evaluación será más desfavorable. Finalmente, la tercera hipótesis formulada fue que a medida que aumenta la frecuencia de visitas a la ciudad, mejora el nivel de satisfacción y con ella la evaluación.

\section{- Análisis estadístico}

Para el análisis cuantitativo se aplicaron 385 encuestas personales, cuyo método de muestreo fue no probabilístico y la elección del elemento muestral se definió según Hernández et al., (1997) como sujetos voluntarios. Son aquellos que acceden a participar en el estudio y su participación es fortuita, aunque se procura una homogeneidad en las variables demográficas, de manera que los resultados obtenidos no obedecen a diferencias del individuo. Las preguntas se formularon bajo la estructura de escala Likert que corresponden a estadística no paramétrica. De igual manera, se formularon preguntas cerradas que permiten hacer análisis de frecuencias, estimación de tasas de participación y análisis de factores.

La prueba piloto de la encuesta se aplicó a 12 personas en condición de consumidor turista. Dentro de la consistencia interna para medir la confiabilidad de las escalas construidas se calculó el Alfa de Cronbach, donde el nivel total del indicador de consistencia interna fue 
de 0,872. Así se demostró la coherencia entre los distintos ítems que conformaron el instrumento.

Los datos fueron procesados utilizando el software SPSS versión 18 y graficados para el análisis mediante el programa Microsoft Office Excel 2007. Para las pruebas Chi cuadrado y las correlaciones se trabajó con un nivel de significancia de 0,05.

\section{Resultados}

Tabla 1. Cambios en la tipología del consumidor turista 2004 - 2010

\begin{tabular}{l|c|c|c|c|c|c|c|c}
\hline \multirow{2}{*}{$\begin{array}{l}\text { Tipologías del } \\
\text { turista }\end{array}$} & \multicolumn{2}{|c|}{ Año 2004 } & \multicolumn{2}{c|}{ Año 2006 } & \multicolumn{2}{c|}{ Año 2008 } & \multicolumn{2}{c}{ Año 2010 } \\
\cline { 2 - 8 } & Frecuencia & $\%$ & Frecuencia & $\%$ & Frecuencia & $\%$ & Frecuencia & $\%$ \\
\hline Negocios & 177 & $46 \%$ & 169 & $44 \%$ & 81 & $21 \%$ & 85 & $22 \%$ \\
Deportes & 54 & $14 \%$ & 27 & $7 \%$ & 19 & $5 \%$ & 12 & $3 \%$ \\
Turismo & 131 & $34 \%$ & 166 & $43 \%$ & 223 & $58 \%$ & 227 & $59 \%$ \\
Otras actividades & 23 & $6 \%$ & 23 & $6 \%$ & 62 & $16 \%$ & 61 & $16 \%$ \\
TOTAL & 385 & $100 \%$ & 385 & $100 \%$ & 385 & $100 \%$ & 385 & $100 \%$ \\
\hline
\end{tabular}

Fuente: Cálculos propios a partir de información secundaria

Tabla 2. Tipologías de Yiannakis y Gibson adaptadas a la clasificación de los turistas que visitaron Villavicencio durante el 2012

\begin{tabular}{l|c|c}
\hline \multicolumn{3}{c}{ Hombre de Acción } \\
\hline ACTIVIDAD & Frecuencia & Porcentaje \\
\hline Actividades nocturnas & 80 & $84 \%$ \\
Turismo de Aventura & 6 & $6 \%$ \\
Deportes Autóctonos & 5 & $5 \%$ \\
Buscar aventuras amorosas & 4 & $7 \%$ \\
SUBTOTAL & 95 & $25 \%$ \\
\hline \multicolumn{2}{c}{ Hombre de Negocios } \\
\hline ACTIVIDAD & Frecuencia & Porcentaje \\
\hline Negocios & 80 & $82 \%$ \\
Conocer la Ciudad & 36 & $37 \%$ \\
SUBTOTAL & 116 & $30 \%$ \\
\hline \multicolumn{3}{c}{ Escapista } \\
\hline ACTIVIDAD & Frecuencia & Porcentaje \\
\hline Descanso & 104 & $60 \%$ \\
Visitar Familia & 40 & $23 \%$ \\
Tour Organizado & 12 & $7 \%$ \\
Visitar Parques & 8 & $5 \%$ \\
Disfrutar Gastronomía & 8 & $5 \%$ \\
Tomar el sol & 2 & $1 \%$ \\
SUBTOTAL & 174 & $45 \%$ \\
\hline
\end{tabular}


Tabla 3. Imágenes turísticas a priori sobre Villavicencio

\begin{tabular}{l|c|c}
\hline \multicolumn{1}{c|}{ Imaginario } & Frecuencia & Porcentaje \\
\hline El Ilano & 102 & 26.5 \\
Una ciudad para negocios & 61 & 15.8 \\
Una ciudad de tierra caliente & 29 & 7.5 \\
Un sitio para deportes de aventura & 1 & 0.3 \\
Una ciudad de actividades nocturnas & 43 & 11.2 \\
Una ciudad de descanso & 69 & 17.9 \\
Una ciudad cultural & 69 & 17.9 \\
Una ciudad para buscar aventuras & 11 & 2.9 \\
TOTAL & 385 & 100 \\
\hline
\end{tabular}

Tabla 4. Expectativas de los turistas al momento de llegar al destino

\begin{tabular}{l|c|c}
\hline \multicolumn{1}{c|}{ Actividad } & Frecuencia & Porcentaje \\
\hline Tomar el Sol & 2 & $0.52 \%$ \\
Turismo de Aventura & 6 & $1.56 \%$ \\
Deportes Autóctonos & 5 & $1.30 \%$ \\
Descanso & 116 & $30.13 \%$ \\
Tour Organizado, & 12 & $3.12 \%$ \\
Actividades nocturnas & 79 & $20.52 \%$ \\
Disfrutar Gastronomía & 6 & $1.55 \%$ \\
Visitar Familia & 29 & $7.53 \%$ \\
Visitar Parques & 8 & $2.08 \%$ \\
Conocer la Ciudad & 36 & $9.35 \%$ \\
Negocios & 86 & $22 ., 34 \%$ \\
Total & $\mathbf{3 8 5}$ & $\mathbf{1 0 0 \%}$ \\
\hline
\end{tabular}

Tabla 5. Valores de prueba Chi Cuadrado

\begin{tabular}{l|c|c|c|c|c|c|c|c}
\cline { 2 - 8 } & $\begin{array}{c}\text { Año } \\
\mathbf{2 0 0 4}\end{array}$ & $\begin{array}{c}\text { Año } \\
\mathbf{2 0 1 0}\end{array}$ & Tipología & $\begin{array}{c}\text { Imagen } \\
\text { Apriori }\end{array}$ & $\begin{array}{c}\text { Imaginario } \\
\text { Genero }\end{array}$ & $\begin{array}{r}\text { Imaginario } \\
\text { Estado } \\
\text { civil }\end{array}$ & $\begin{array}{c}\text { Imaginario } \\
\text { Frecuencia } \\
\text { de visita }\end{array}$ & $\begin{array}{c}\text { Imagen } \\
\text { Expectativa }\end{array}$ \\
\hline $\begin{array}{l}\text { Chi-cuadrado } \\
\text { Grados de }\end{array}$ & 154,584 & 265,587 & 26,0935 & 164,7974 & 27,707 & 23,931 & 50,0257 & 116,1762 \\
libertad & 3 & 3 & 2 & 7 & 7 & 7 & 7 & 9 \\
Sig. asintótica & 0 & 0 & 0 & 0 & 0,00024 & 0,00117 & 0,00036 & 0 \\
\hline
\end{tabular}

Tabla 6. Valores correlaciones Spearman

\begin{tabular}{l|c|c|c}
\hline Variables & Imagen y Expectativa & Expectativa y Evaluación & Fidelidad y Satisfacción \\
\hline Coeficiente & 0,836 & 0,342 & 0,005 \\
Error & 0,019 & 0,046 & 0,056 \\
Nivel de significancia & 0 & 0 & 0,916 \\
\hline
\end{tabular}




\section{Discusión de resultados}

En los años transcurridos durante el periodo 2004 - 2010 se presentaron cambios en las actividades que los consumidores turistas vienen a desarrollar en la ciudad. Ellos son presentados en la tabla 1 . Se evidencia que algunas tipologías crecen mientras otras decrecen en peso porcentual. En el primer grupo se encuentran, por una parte, la tipología denominada turismo, que presenta gran dinamismo y registra un crecimiento del $73,5 \%$ en el periodo observado $y$, por otra parte, la tipología de otras actividades, que registra en el mismo lapso un cambio del cuarto lugar al tercero en términos de importancia porcentual. En contraposición, las tipologías de negocios pasan del primer lugar en el 2004, al segundo en el 2010, con una pérdida del $53 \%$. Y la mayor pérdida de representación se encuentra en la tipología deportes, que otrora figuraba en el tercer lugar y posteriormente ocupó el último, con un descenso del 79\% para el periodo 2004-2010.

Estos resultados junto al valor Chi cuadrado presentado en la tabla 5, permiten afirmar que durante el lapso 2004 - 2010, en Villavicencio sí existe un cambio en las tipologías de consumidores que llegan a la ciudad, y que las diferencias significativas en la tipología de las actividades que realizan los turistas evidencian un cambio en el consumidor a lo largo del tiempo. Lo anterior justifica el estudio de sus perfiles con el fin de ser una fuente de oportunidades de mejora continua en la satisfacción del turista mediante la reconstrucción de la oferta del destino, ajustándola y alineándola a las expectativas con que arriban los usuarios.

Comparación de las tipologías de Yiannakis y Gibson frente a los segmentos planteados por la Agenda Interna de Productividad y Competitividad

Yiannakis y Gibson proponen en 1992 diez tipologías diferentes para entender los consumidores turistas. La investigación demuestra que a Villavicencio arriban segmentos que pueden ser identificados según tres de esas tipologías y cuyos resultados pueden observarse en la tabla 2. En primer lugar se encuentra un segmento conformado por consumidores turistas que buscan diversión nocturna y un destino con actividades de riesgo; corresponden a la tipología denominada Hombre de Acción y representan el $25 \%$ del total. Esta tipología no es comparable con ningún segmento planteado por el documento de Agenda interna de productividad y competitividad del Departamento del Meta elaborada en el año 2005. En segundo lugar, se encuentra el grupo correspondiente a los denominados hombres de negocios, cuyas motivaciones están orientadas a la realización de actividades menos arriesgadas y que buscan un beneficio económico. Ellos alcanzan el 30\% y según la agenda del departamento son identificados como segmento de negocios. Otro grupo, uno más heterogéneo, muestra las amplias posibilidades del turismo, se trata de los denominados Escapistas; las personas pertenecientes a este último segmento se encuentran dispuestas a descansar y visitar la familia, aunque disfrutan de los parques, los paseos guiados y la gastronomía. Son el grupo más grande debido a lo diverso de sus intenciones y expectativas, representando el $45 \%$ de los perfiles que arriban a la ciudad para satisfacer sus necesidades de ocio y, en los grupos identificados por el departamento es equivalente al turismo familiar.

La categoría de turismo social propuesta en el documento de la Gobernación del departamento no fue validada como similar a alguna tipología encontrada en la investigación.

El análisis univariado presentado en la tabla 5, indica que entre las tipologías que arriban a Villavicencio existen diferencias y ellas 
permiten clasificar al consumidor en conglomerados diferentes. Por ello, es válido diseñar procesos de segmentación ya que como lo planteó en 1956 Wendell Smith (Citado por Rivera De Garcillán, 2012), el proceso de segmentación consiste en la división del mercado a través de diferentes procedimientos estadísticos en una serie de subconjuntos a partir de una o más variables que son tomadas como referencia para explicar comportamientos diferenciados de unos y otros.

\section{Relación entre la imagen de Villavicencio como destino y las expectativas del consumidor turístico}

La actividad turística se desarrolla, en gran medida, gracias a las motivaciones que brindan las imágenes turísticas, al respecto Camprubí et al., (2009) sostienen que la imagen turística es "una construcción mental donde la representación visual se sitúa en un segundo plano frente a factores relacionados con el conocimiento, impresiones y creencias que el turista tiene sobre un destino turístico determinado".

Bajo esta perspectiva, la imagen turística tiene la capacidad de influir en la toma de decisiones de un consumidor en el momento de seleccionar un destino. Debido a que las imágenes se crean en la mente del individuo, son hechos cargados de subjetividad. Galí y Donaire (2005) definen las imágenes percibidas a priori como la construcción mental antes de visitar el destino. En este sentido, la representación que los turistas tienen de Villavicencio es importante pues "la imagen que se construya de la ciudad, es un elemento estratégico para el posicionamiento y competitividad del destino turístico" (Gartner, 1993; Govers y Go, 2004).

Los resultados de la imagen turística sobre Villavicencio son presentados en la Tabla 3. En ella, el primer lugar lo ocupa El Ilano, representado en su inmensidad, sus paisajes y puesta del sol. Esta imagen tiene como fuente de información la publicidad boca-boca, que se convierte en una forma de comunicación de imágenes inducidas a posteriori (Suvantola, 2002). Es decir, que el destino fue referenciado por alguien que lo visitó, y capturó mediante fotografías, imágenes que han sido divulgadas de forma promocional a través de diferentes medios de comunicación, para algún evento específico. De esta forma, la fotografía icónica reafirma la vivencia que se espera encontrar en el destino.

La segunda imagen en importancia porcentual es la ciudad como un destino cultural, donde encontrará espectáculos folclóricos como danzas, música, comidas típicas, entre otras manifestaciones propias de la cultura llanera. Igual importancia porcentual a la anterior obtuvo el imaginario de Villavicencio como una ciudad para descansar, y luego es vista como una ciudad propicia para el desarrollo de los negocios.

En menor proporción se observa en la tabla 3 que los imaginarios de Villavicencio son: una ciudad de tierra caliente, un destino conveniente para las aventuras amorosas o los deportes de aventura.

Para Miossec (1977) existen tres clases de imágenes emitidas: las universales, las efímeras y las inducidas. Para el caso de quienes consideran que Villavicencio es El Llano, la mayoría respondió que su decisión de visitar la ciudad fue por conocimiento propio, es decir motivados por imágenes universales. Continúan en este orden, las personas que usan como fuente de información la televisión cuyas imágenes se consideran efímeras. Por último, se encuentra la información contenida en la página Web del Instituto de Turismo Municipal que corresponde a las imágenes inducidas.

Quienes tienen a la página web del Instituto de 
Turismo Municipal como fuente de información, afirman que lo contenido allí era alusivo a figuras icónicas del Llano como baile, música y deportes autóctonos. Aquello constituye una imagen inducida por el propio ente de gobierno, y por tanto, una fuente creíble.

Los resultados de las pruebas de Chi cuadrado evidencian la existencia de diferencias en los imaginarios acerca de lo que es la ciudad de Villavicencio para los turistas. Esto permite afirmar que al analizar el consumidor, no solo por tipo de turistas, sino por los diferentes imaginarios, se encuentran diversas expectativas acerca de su futura estadía.

La tabla 4 presenta las expectativas que los consumidores turistas tienen en el momento del arribo al destino, es decir, la razón principal del viaje según la categorización elaborada por la Organización Mundial del Turismo.

Los resultados confirman que las actividades planeadas para desarrollar en Villavicencio por parte de los consumidores, se organizan en tres grupos de expectativas, coincidiendo con las mismas actividades que explican la segmentación según las tipificaciones de Yiannakis y Gibson. La más grande de ellas es el descanso, el cual se configura en el principal motivo de viaje indistintamente de alguna variable demográfica como el género, la edad o el nivel socioeconómico. Los negocios son la segunda intención de visita. Finalmente el tercer grupo lo representan las actividades nocturnas. Estas tres actividades reúnen más del $70 \%$ de las razones argumentadas para realizar turismo en Villavicencio.

Estudios similares describen la importancia de analizar la imagen en un intento por mejorar la promoción y comercialización de los destinos turísticos. Para San Martín et al. (2006) los individuos utilizarán las distintas dimensiones de la imagen -de naturaleza cognitiva y afectiva- para comparar los destinos evocados en su mente durante el proceso de elección y seleccionar en última instancia, el lugar a visitar. Esta conclusión es compartida por Pons et al., (2007) quienes afirman que la imagen es el elemento fundamental y determinante en la formación de los diferentes conjuntos de elección, a partir de los cuales se realiza la elección definitiva. En esta misma línea, para Traverso y Román (2006) resulta necesario conocer la evolución de los deseos y necesidades de los diferentes grupos de interés, ya que a medida que estos sean satisfechos, la configuración de la imagen tendrá un signo u otro.

\section{Relación de las expectativas y la evaluación de Villavicencio como destino turístico}

Para Panosso (2007), el turismo es experiencia y las impresiones internas de esa acción no se forman sólo en el viaje o en el desplazamiento propiamente dicho, sino también son vividas en los momentos que anticipan el acto del turismo y en los momentos que prosiguen después que el "ser" turista ha emprendido su viaje.

Así, las expectativas sobre Villavicencio como destino turístico se forman en la mente de los consumidores y dependen en gran medida de la imagen a priori que éstos tienen, especialmente en su primera visita.

Ahora, al analizar la relación entre las expectativas y la evaluación del destino se tuvieron en cuenta dos momentos importantes. El primero se presenta en el sitio de origen en el cual se puede plantear la primera hipótesis: cuanto más favorable sea la imagen percibida a priori del destino turístico, mayores serían las expectativas del individuo sobre su futura experiencia turística. El segundo momento es la visita turística en el destino y en este se plantean dos hipótesis: por un lado, cuanto mayores fueran las 
expectativas de los consumidores turísticos, menor sería la evaluación que hacen de su satisfacción del destino; y por el otro, a medida que aumenta la frecuencia de visitas a la ciudad, mejora el nivel de satisfacción y con ella la evaluación del destino.

En lo referente a la correlación de las variables imagen y expectativas, en la tabla 6 los resultados de la correlación de Spearman permiten concluir que la expectativa sí es una variable dependiente de la imagen a priori. Ello significa que, como afirman Kim y Richardson (2003), las impresiones, creencias, ideas, expectativas y sentimientos hacia un lugar se acumulan a lo largo del tiempo. Esta formación de una imagen a priori se hace cuando confluyen los dos componentes que forman las imágenes en la mente de un consumidor, el componente cognitivo, y el afectivo.

Frente al componente cognitivo, se pudo determinar que las imágenes universales, efímeras e inducidas han generado en la mente de los consumidores, un estereotipo y un imaginario errado de Villavicencio. Por esto, los turistas tienen unas expectativas muy altas, frente a la realidad natural y arquitectónica del destino. De este modo, la causa y el propósito del viaje, que constituyen el componente afectivo, pueden ser objeto de una expectativa que no concuerda con las condiciones de la ciudad.

Como complemento a este análisis, el rol que desempeñan los operadores turísticos dentro del sistema de turismo debe ser realzado. Según Giraldo y Otero (2012) ellos promueven el consumo del turismo contribuyendo en la generación de actitudes positivas y en la formación de una imagen apropiada acerca del destino turístico. Por lo anterior, es necesario cuidar el proceso de comunicación que se hace de Villavicencio como destino turístico, puesto que el consumidor turista solo dispone de esa comunicación para fijarse una imagen de la ciudad y este tipo de productos turísticos.

En la tabla 6 también se presentan los resultados de la correlación de Spearman para las variables expectativas y evaluación. Su bajo coeficiente debe interpretarse como una correlación con una dependencia baja y positiva, lo que no es concordante con la segunda hipótesis planteada, puesto que en ella se consideraba que mientras más altas las expectativas menor era la evaluación.

Este resultado es coherente con investigaciones similares en destinos como la Gran Canaria, donde un estudio analizó de forma separada el componente cognitivo de la imagen y el componente afectivo de la misma. El resultado fue una correlación positiva. La conclusión fue que los turistas que tienen una mayor experiencia con el destino por haberlo visitado en más de una ocasión, evalúan de manera más positiva al mismo (Moreno et al., 2006).

Frente a la tercera hipótesis, como el coeficiente de la correlación entre las variables fidelidad y satisfacción presentado en la tabla 6 tiende a cero, se puede afirmar que la satisfacción con el destino turístico y la fidelidad en la frecuencia de visitas son variables independientes en el análisis para Villavicencio.

Por lo anterior es necesario continuar con la medición de la evaluación que el turista hace de la ciudad, tal como lo expresan Swarbrooke y Horner (2002). Ellos afirman que se sabe cuándo intervenir en el proceso identificando quién será el objetivo para el producto turístico, en un momento dado, basados en el conocimiento de los patrones de comportamiento; con el fin de obtener los resultados deseados. 


\section{Conclusión}

Para Villavicencio como destino turístico, la expectativa de viaje es una variable dependiente de la imagen a priori que tienen los consumidores turísticos, y la actividad más buscada por ellos para desarrollar en la ciudad es, el descanso, en un 30.13\%.

A partir de lo anterior, los autores recomiendan que la estrategia de comunicación se debe orientar al aprovechamiento de las potencialidades naturales y culturales que ofrece la ciudad, donde la congruencia del contenido del mensaje (naturaleza-descanso), debe convertirse en el hecho generador de la visita.

\section{Agradecimientos}

A la Universidad de los Llanos por financiar esta investigación, la cual fue fundamental para la obtención del título de Maestría en Mercadeo otorgado por la Universidad de Manizales a dos de los autores.

\section{Referencias}

Agenda Interna de Productividad y Competitividad del Meta 2005; [15 de Mayo de 2011] URL: http://sistemactimeta. gov.co/wp-content/uploads/2011 /06/Agenda-Interna-de-Productividad-yCompetitividad-Meta.pdf.

Camprubí R, Guia J, Comas J. La formación de la imagen turística inducida: Un modelo conceptual. Pasos Revista De Turismo y Patrimonio Cultural. 2009; 7: 225-270.

Galí-Espelt N, Donaire-Benito JA. La construcción social de la imagen de Girona: un enfoque metodológico. Gestión de turismo. 2005; 26(5): 777-785
Gartner WC. Image formation process. Journal of travel and tourism marketing, 1993; 2: $191-216$.

Giraldo-Pérez W, Otero-Gómez M. El sistema de turismo, superando la relación de oferta y demanda. Rev Episteme. 2012; 3:16-23.

Govers R, Go FM. Cultural Identities Constructed, Imagined and Experienced: A 3-gap.Tourism Destination Image Formation Model, Tourism - An International Interdisciplinary Journal. 2004; 52(2): 165-182.

Hernández SR, Fernández CC, Baptista LP. 1997. Metodología de la investigación. $2^{\text {a }}$ Edición. Edit. McGraw Hill, Bogotá, p.505.

Kim H, Richardson SL. Motion picture impacts on destination images. Annals of Tourism Research. 2003; 30(1): 216-237

Ministerio de Comercio Industria y Turismo. Definición del sector turismo en Colombia; [14 de Enero de 2013] URL: https://www. mincomercio.gov.co/minturismo/publicaci ones. php id $=16273 \& d$ Print $=1$

Miossec, J. M. 1977. Un modèle de l'espace touristique. Espace géographique, Tomo 6 v. $1: 41-48$.

Moreno-Gil S, Beerli-Palacio A, MartínSantana JD. La imagen de Gran Canaria como destino turístico. Revista Vector Plus. 2004; 31:71-78.

Panosso Netto. A. Filosofía del turismo: Una propuesta epistemológica. Estudios y perspectivas en turismo2007; [12 de Diciembre de 2012] http://www.redalyc. org/articulo.oa?id=180713898001

Páramo MD. 2004. Marketing su esencia conceptual. $1^{\text {a }}$ Edición. Ediciones Uninorte, Barranquilla, p.219. 
Pons RC, Morales-Morales L, Díaz-González Y. La imagen del destino y el comportamiento de compra del turista. Revista teoría y praxis. 2007; 3: 89-102.

Rivera C J, de Garcillan LM. 2012. Dirección de marketing, fundamentos y aplicaciones $3^{\text {a }}$.Edición. Editorial ESIC. Madrid. pág. 86

San Martín-Gutiérrez $\mathrm{H}$, Rodríguez del Bosque-Rodríguez I, Vásquez-Casielles R. Análisis de la imagen en turismo mediante técnicas estructuradas y no estructuradas: implicaciones competitivas para los destinos turísticos. Revista asturiana de economía. 2006; 35: 69-91.

Selltiz C, Jahoda M, Deutsch M, Cook SW. 1974. Research methods in social relations. New York, p.622. Holt, Rinehart y Winston Publishing.

Sheeran P, Abraham Ch. 1996. The health behavior Models. En: Norman y Conner, (Eds.), predicting health behaviors (p. 2361). Philadelphia: Plenium Pres.

Suvantola J. 2002. Tourist's Experience of Place.1 st ed. Burlington, Ashgate Publishing, p.297.

Swarbrooke J, Horner S. 2011. O comportamento do consumidor no turismo. $2^{\text {a }}$ reimpressão. Editora Aleph, São Paulo, p. 405.

Traverso-Cortes J, Román-Onsalo, M. Desarrollo de la imagen de un destino turístico. Modelo de gestión. Instituto de Investigaciones de la Facultad de Ciencias Económicas y Sociales. 2006; 25: 42-68

Yiannakis A, Gibson H. Roles tourists play. Annals of tourism research. 1992; 19(2): 287-303. 